\title{
FARINHA, TRADIÇÃO ALIMENTAR DOS POVOS DA FLORESTA
}

\author{
Érico Silva Alves Muniz (D) $\triangle$ \\ Universidade Federal do Pará - Campus Bragança \\ Edson Gabriel Dias (D) $\triangle$ \\ Universidade Federal do Pará - Campus Bragança
}


Desde longa data, as Ciências Sociais debatem que a alimentação humana ultrapassa suas funções físicas e biológicas e insere-se nos campos mitológicos, religiosos e sagrados, representando uma série de interpretações e cosmovisões de determinados grupos sociais. Na Amazônia não é diferente, os atos de comer e de preparar os alimentos com seus signos e símbolos manifestam ideias, padrões e crenças dos povos que habitam a floresta. Hábitos e costumes alimentares correspondem, portanto, a elementos de grande importância para a construção das identidades e sensações de pertencimento (Viveiros de Castro 1996, Pacheco 2017).

Caracterizada pelo pensamento social brasileiro como a de mais forte herança indígena, a alimentação amazônica é composta por complexas teias de inter-relações socioculturais e históricas, marcada pelas trocas de saberes e técnicas tradicionais herdadas dos povos nativos da região, perpetuadas e modificadas por meio da oralidade durante séculos (Castro 1948). Nesse universo amazônico, a centralidade das refeições quase sempre recai sobre a mandioca. Nas fotos apresentadas neste ensaio fotográfico observamos, por meio das pesquisas de campo realizadas em projeto de pesquisa e extensão universitária, que em todo processo de produção e consumo da farinha de mandioca há presença significativa dos conhecimentos tradicionais adquiridos por meio de sofisticada observação dos fenômenos da natureza.

A farinha, como marco das culturas alimentares amazônicas, incide na expressão de diversos significados, memórias e mitos, sendo um dos principais elementos na construção das identidades coletivas e regionais. Presente em quase todas as mesas, a farinha de mandioca representa também a soberania alimentar de comunidades tradicionais (indígenas, quilombolas e ribeirinhas) e da agricultura familiar, pois sua produção representa o direito de poder expressar seus hábitos e cultivar seus próprios alimentos (Muniz \& Dias 2019).

\section{REFERÊNCIAS}

Viveiros de Castro, E. 1996. Os pronomes cosmológicos e o perspectivismo ameríndio. Mana 2 (2): 115-144.

Castro, J. 1948. Geografia da fome. 2. ed. Rio de Janeiro: O Cruzeiro.

Muniz, E. S., Dias, E. G. 2019. Farinha como patrimônio: saberes e indicação geográfica no Nordeste paraense, in Direitos dos povos e comunidades tradicionais e povos indígenas em contextos de retrocessos. Editado por Brito, C. S, pp. 75-88. Curitiba: Editora CRV.

Pacheco, A. S. 2017. No tempo das festas: sociabilidades e conflitos em cidades e florestas Marajoaras. Projeto História 58: 9-44. 


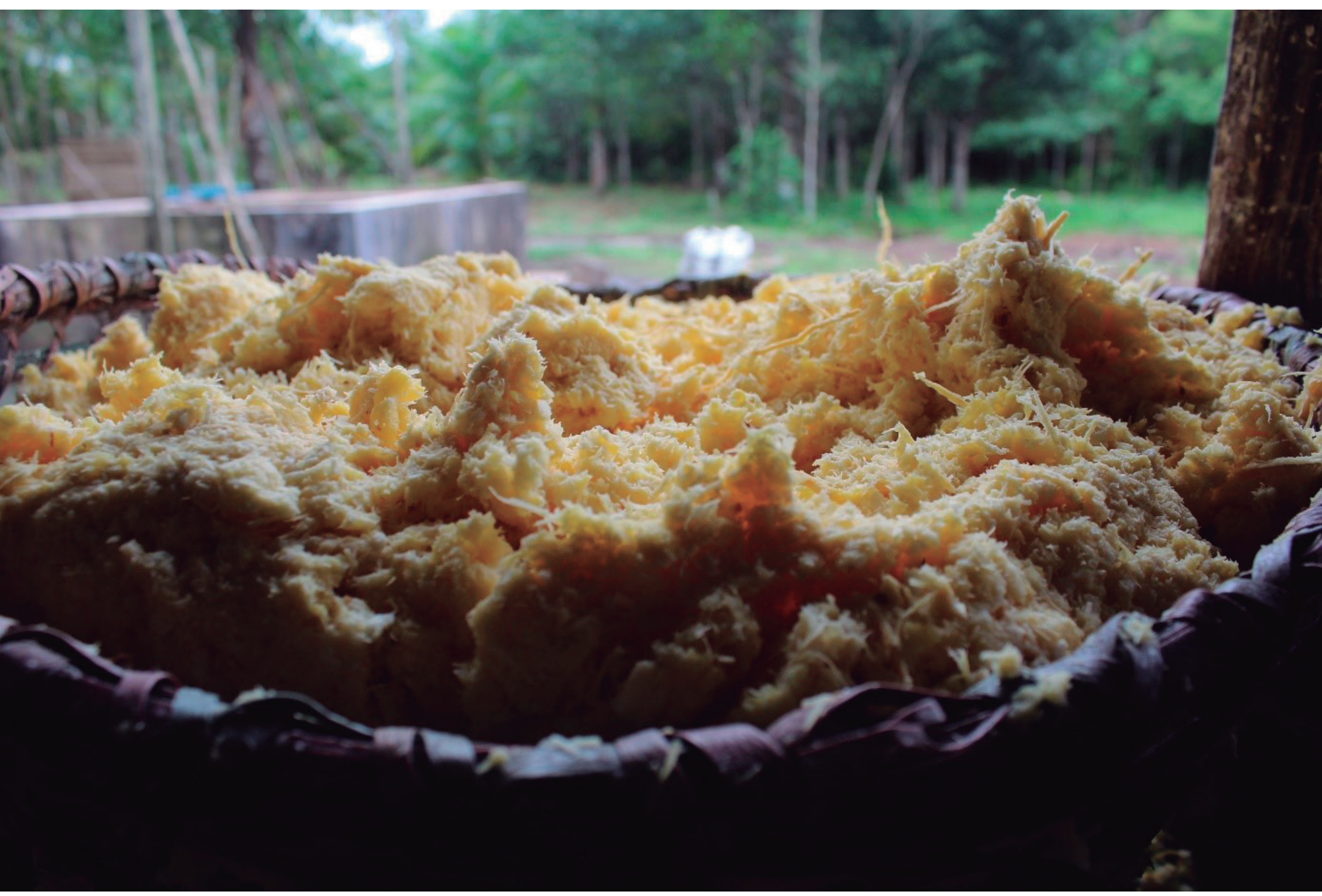

Figura 2: Do igarapé para a casa de farinha. Foto: Edson Gabriel Dias (2019). 

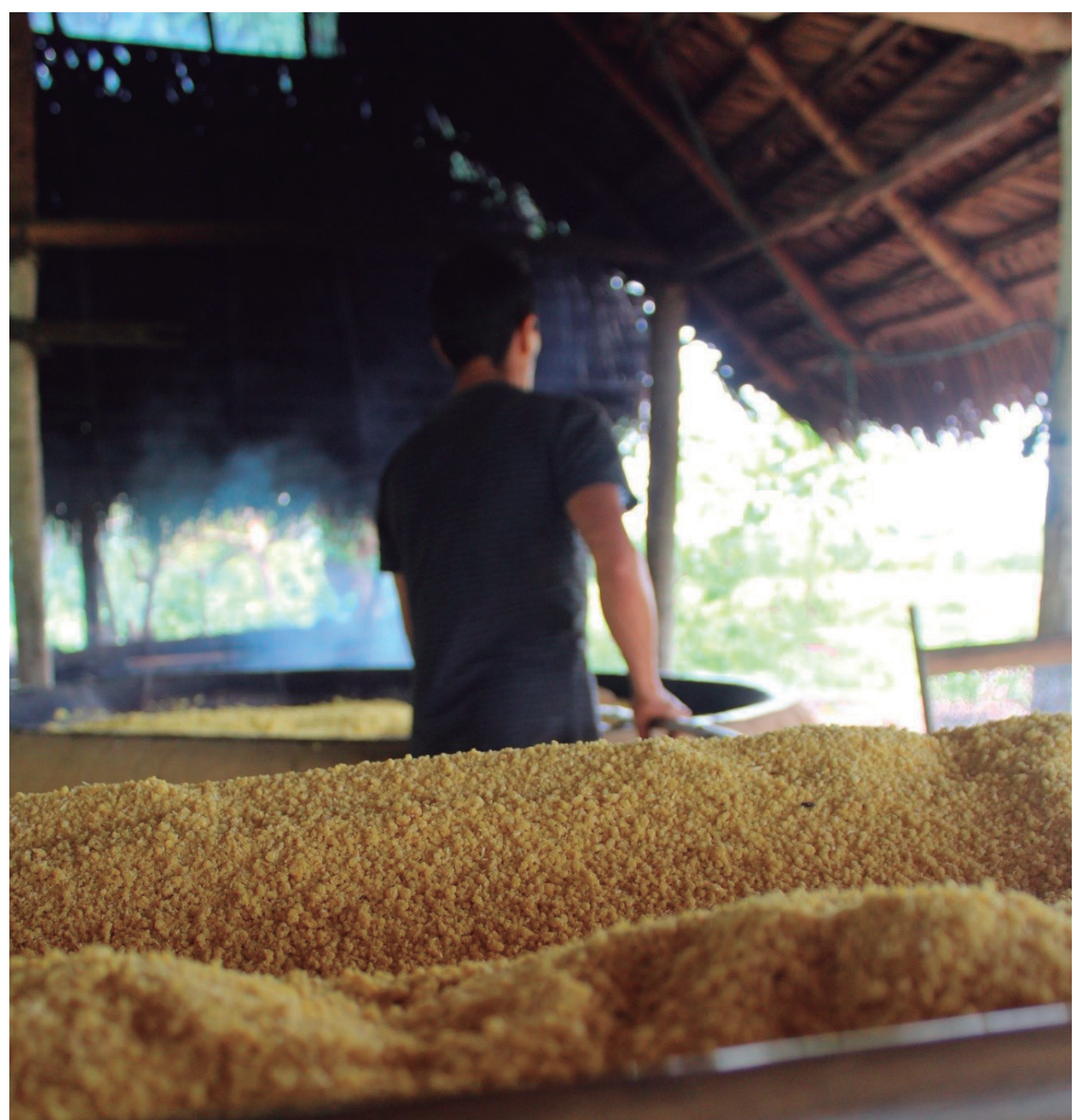

Figura 4: Farinha d'água de Bragança. Foto: Edson Gabriel Dias (2019). 


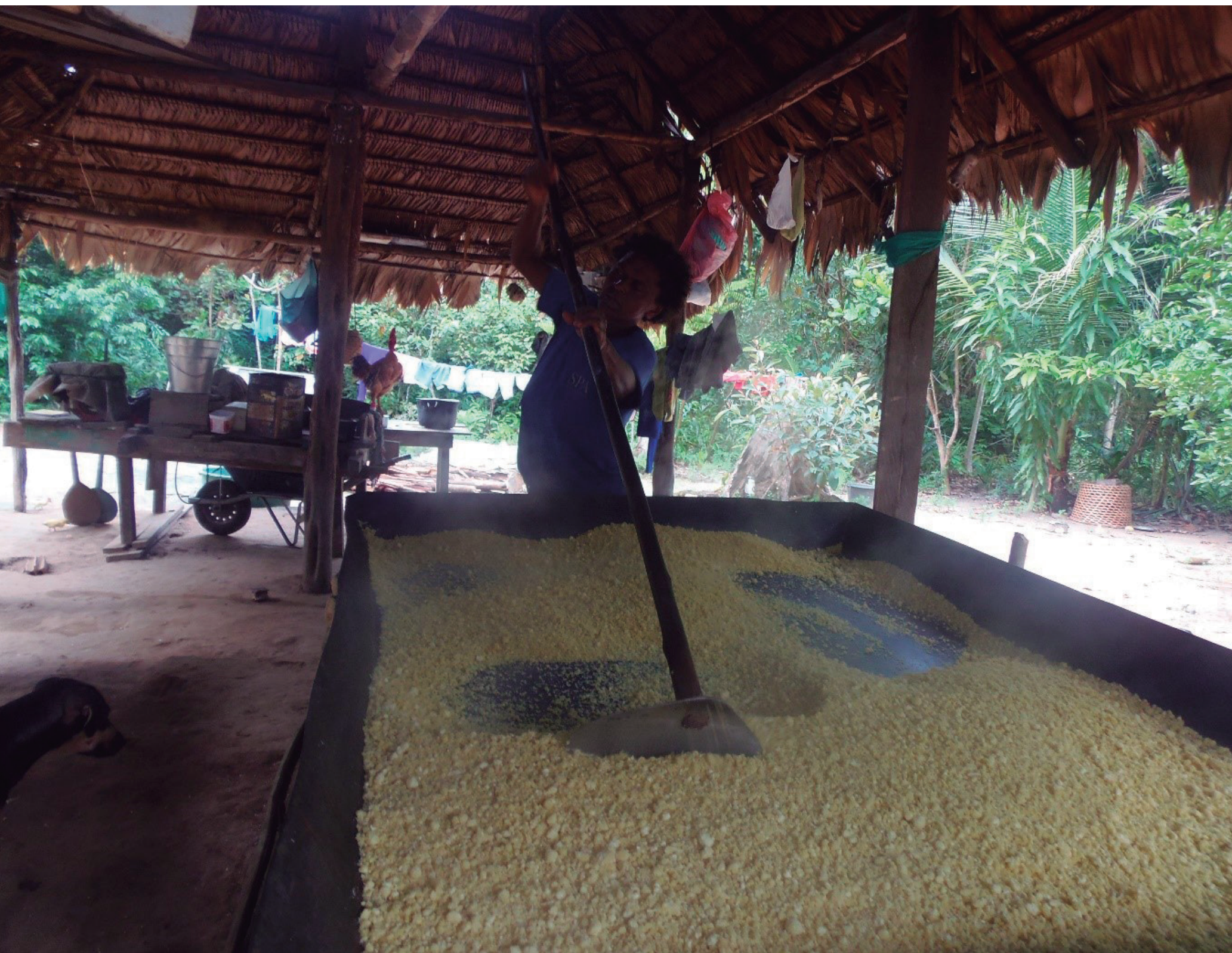

Figura 5: Saber torrar. Foto: Érico Silva Muniz (2019). 


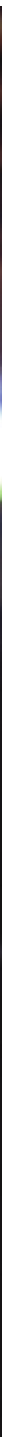

Figura 6: Mandioca, cores e formas. Foto: Edson Gabriel Dias (2019). 


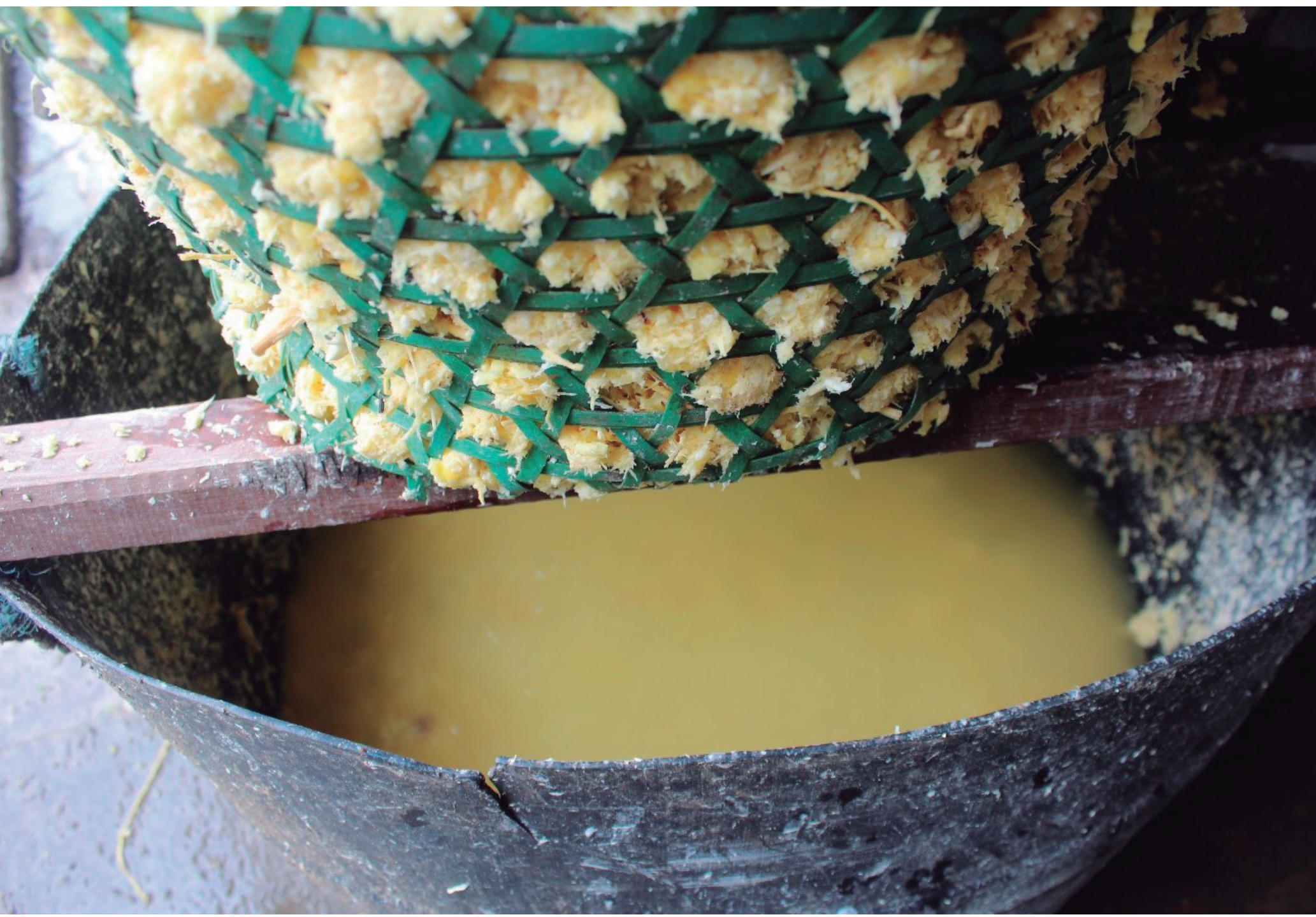

Figura 7: Os utensílios e os saberes da floresta: Foto: Edson Gabriel Dias (2019). 
volume 13 (1) | 447 - 456 | 2021

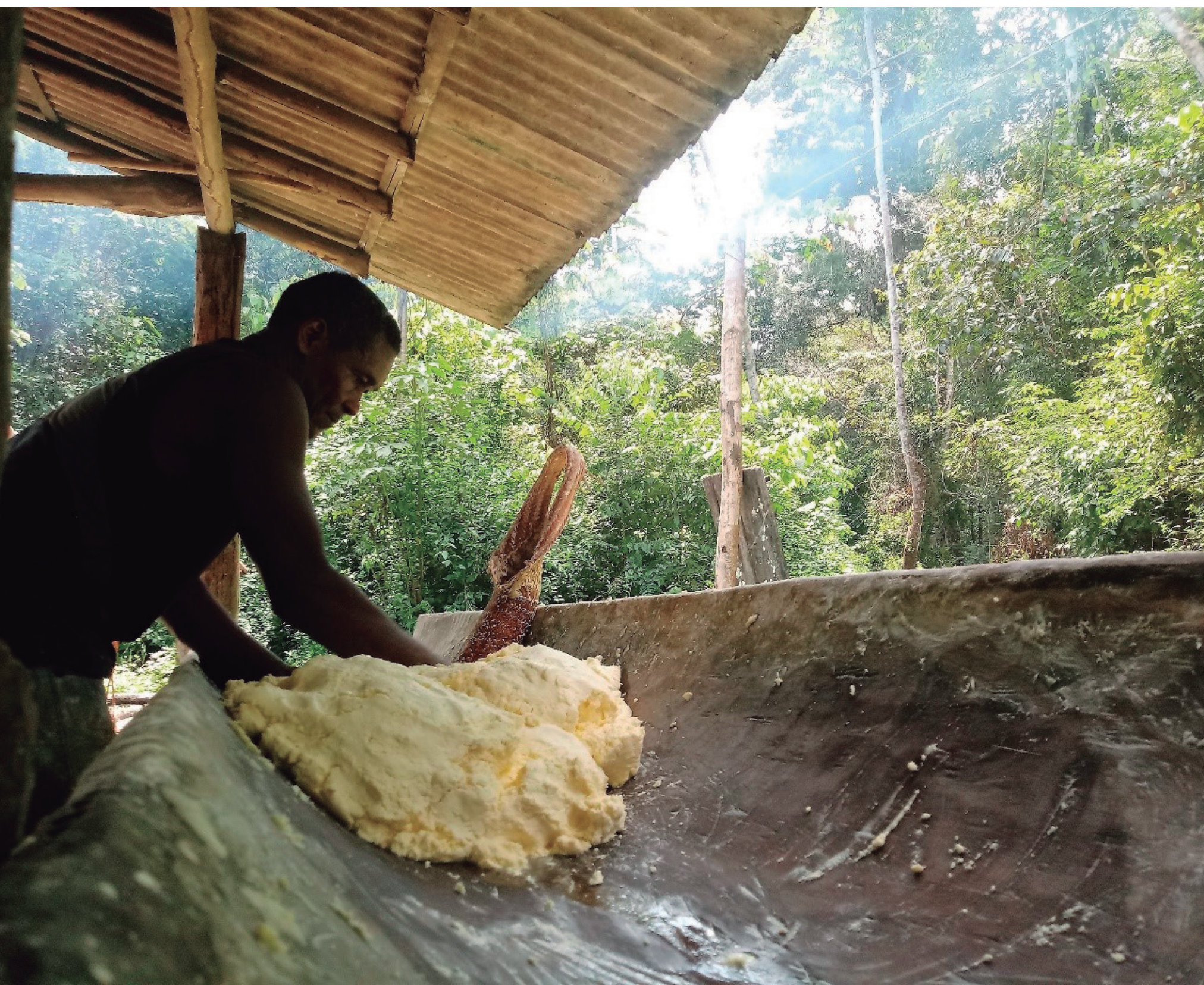

Figura 8: Massa na canoa. Foto: Edson Gabriel Dias (2019). 